Full Length Article

\title{
Analysis of induced stress on materials exposed to laser-plasma radiation during high-intensity laser experiments
}

\author{
M. Scisciòo, ${ }^{a}$, M. Barberio ${ }^{a, b, c}$, C. Liberatore ${ }^{a}$, S. Veltri ${ }^{a, c, d}$, A. Laramée $^{a}$, L. Palumbo $^{\mathrm{d}}$, \\ F. Legaré ${ }^{a}$, P. Antici ${ }^{a, d, *}$ \\ a INRS-EMT, 1650 Boul. Lionel Boulet, Varennes, Canada \\ b Secondary Sources Divisions, ELI-ALPS,Tsiza Lajos krt, 85-87, Szeged, Hungary \\ ${ }^{\mathrm{c}}$ University of Calabria, via Bucci $4 \mathrm{~B}$, Rende, CS, Italy \\ d INFN-RM1 E' University of Rome “La Sapienza”, P.zzale A. Moro 2, 00185 Rome, Italy
}

\section{A R T I C L E I N F O}

\section{Article history:}

Received 14 October 2016

Received in revised form 1 December 2016

Accepted 1 December 2016

Available online $\mathrm{xxx}$

\section{Keywords:}

Laser-matter interaction

Stress testing of materials

High-intensity laser

Laser-plasma radiation

\begin{abstract}
A B S T R A C T
In this work, we investigate the damage produced in materials when exposed to a laser-generated plasma. The plasma was generated by interaction of a high-intensity laser with Oxygen. We demonstrate that the stress induced on the target surface of a Tantalum target (typical materials used as Plasma Facing Material) after $10 \mathrm{~h}$ of plasma exposure is equivalent to the stress induced during $1 \mathrm{~h}$ of conventional laser ablation using a pulsed $0.5 \mathrm{~J}$ laser. In both cases we obtain a surface erosion in the tens of $\mu \mathrm{m}$, and a change in the surface roughness in the tens of $\mathrm{nm}$ for the stressed materials. The erosion rate of $1 \mathrm{~nm} / \mathrm{s}$, explained in terms of surface fragmentation at thermodynamic equilibrium, generates a slow damage to the materials exposed to the plasma. Our method allows indicating safety parameters for the maintenance of materials used in high-intensity laser experiments.
\end{abstract}

(C) 2016 Published by Elsevier B.V.

\section{Introduction}

The advent of high-power ultra-short lasers has opened up the field of laser-driven particle acceleration, in particular proton and electron acceleration [1,2]. The investigation of these laser-accelerated beams and its use is currently challenging many research laboratories worldwide, in particular for the improved characteristics of these sources such as compactness, versatility and tunability. As an example, intense research has been conducted on the topic of laser-accelerated proton beams, produced during the interaction of a high-intensity $\left(\mathrm{I}>1 \times 10^{18} \mathrm{~W} / \mathrm{cm}^{2}\right)$, short pulse $(<\mathrm{ps})$ laser with a solid target [3]. Nowadays, proton beams with very interesting characteristics are routinely produced exhibiting in some cases features that outperform conventional radio-frequency-based accelerators (typical laser-driven proton beams can generate up to $10^{13}$ particles per shot, having a bunch duration of $\mathrm{ps}$ at the source, reaching energies in the tens of $\mathrm{MeV}$ range [4] and presenting a very good laminarity [5]). While strong effort is put to materialize different applications for laseraccelerated beams such as in astrophysics [6], as bright ultra-short

\footnotetext{
* Corresponding author at: INRS-EMT, 1650, Boul. Lionel Boulet, Varennes, Canada. E-mail address: antici@emt.inrs.ca (P. Antici).
}

neutron source $[7,8]$, or medicine [9], research in optimizing the infrastructure where these experiments take place (and in particular target chambers and their general safety parameters for higher repetition rate experiments) is still in an embryonic state. All the laser-driven acceleration mechanisms are based on a highintense laser-matter interaction, which generates an energetic plasma inside the target chamber. The plasma generation is associated with the production of electromagnetic pollution, gamma, $\mathrm{X}$-ray, and beta radiation. All these side effects can damage the plasma-exposed materials; materials at risk include more delicate optical components (coatings) but also the first walls of the target chambers, with serious consequences for the robustness of the equipment and the safety of the operators.

In this paper we study the stress induced on the surface of Tantalum when exposed to a strong plasma generated by the interaction of a high-intensity laser with oxygen. The observed plasma is typical of laser-matter interaction experiments such as laser driven electron acceleration [10], X-rays [11], or high harmonic generation [12]. We analyze the behavior, under plasma exposure, of Tantalum, since, as suggested by literature $[10,11]$, it is a good candidate for realizing composites structures for Plasma Facing Materials (PFM): Tantalum has a melting point of $3017^{\circ} \mathrm{C}$, higher than the maximum working temperature estimated for typical PFM (about $1500^{\circ} \mathrm{C}$ ). 
A)

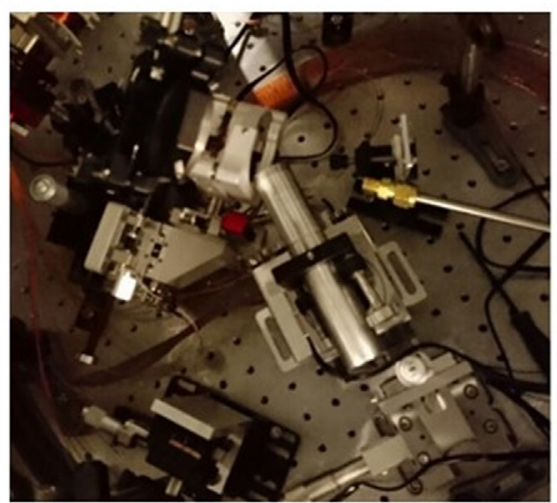

C)

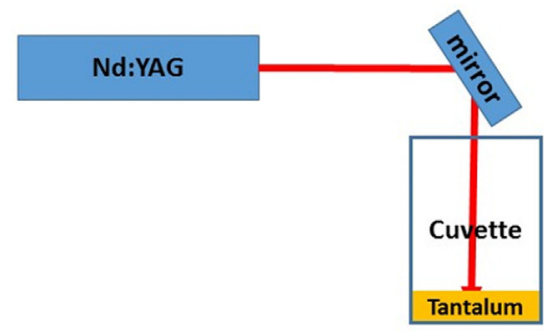

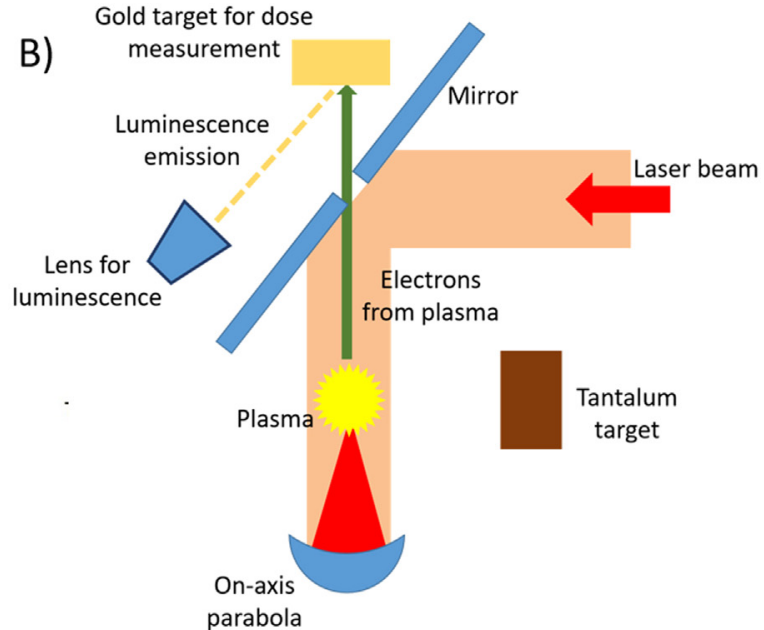

D)

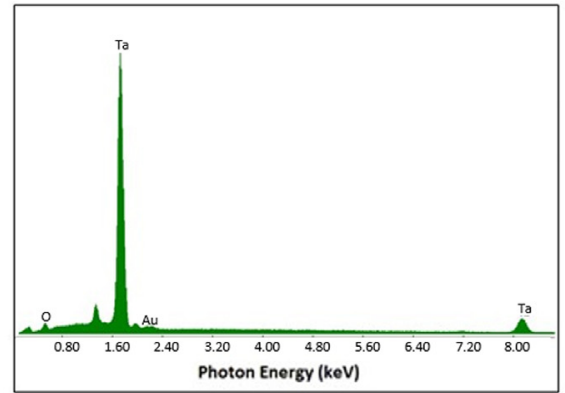

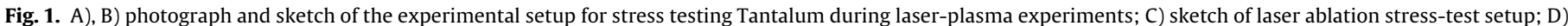
EDX analysis on the Tantalum target.

Finally, the stress generated on the Tantalum surface by the plasma is compared with stress induced by conventional Laser Ablation to better understand the underlying damaging mechanisms.

\section{Methods}

A photograph and sketch of the experimental setup for the plasma generated stress is illustrated in Fig. $1 \mathrm{~A}$ and B while Fig. $1 \mathrm{C}$ shows a sketch of the setup for stress-testing a sample using conventional laser ablation. For the plasma-generated stress testing method, the oxygen plasma was produced by interaction between a high-energy laser and oxygen $\left(\mathrm{O}_{2}\right)$. The Advanced Laser Light Source (ALLS) few-cycle infrared (IR) beamline was used to obtain the oxygen plasma. The source provides a $3 \mathrm{~mJ}$, $15 \mathrm{fs}$ laser pulse, central wavelength of $1.8 \mu \mathrm{m}$ with a repetition rate of $100 \mathrm{~Hz}$. The energy stability of the pulse is approximately $2.5 \%$ rms [13]. The experimental setup, shown in Fig. 1A, consists of a series of transport optics, an on-axis parabola, and a series of imaging lines for the plasma analysis. The plasma was generated in a vacuum chamber (base pressure 0.01 Torr) filled with 3 Torr of pure oxygen. The Tantalum target (Manufactured by Goodfellow and having a purity of 99.99\%, see EDX analysis in Fig. 1D) with dimensions of $2 \mathrm{~cm} \times 2 \mathrm{~cm}$ was placed in front of the plasma for a cumulative duration of about $10 \mathrm{~h}$ at a fixed distance of $4 \mathrm{~cm}$ in order to cover the entire target area with the plasma radiation.

The energy of plasma-emitted electrons was estimated studying the luminescence induced by the plasma radiation on a Gold target (Manufactured by Goodfellow with purity 99.9\%). The luminescence emission was stimulated by the portion of plasma radiation collected through a hole with a diameter of $6 \mathrm{~mm}$ that was located in a mirror placed at $6 \mathrm{~mm}$ from the plasma. Luminescence emis- sion at an angle of $45^{\circ}$ was collected by a lens positioned at $4.5 \mathrm{~cm}$ from the irradiated target (focal distance) and transferred through an optical fiber to a spectrometer working in the UV-vis range (VIS-140 Horiba).

The Laser Ablation stress test was induced ablating the Tantalum target with the first harmonic $(1064 \mathrm{~nm})$ of a pulsed YAG:LASER (7100 series of QUANTA SYSTEM). The laser spot size diameter on the target surface was about $1 \mathrm{~cm}^{2}$, while the laser energy was fixed at $500 \mathrm{~mJ} /$ pulse with a repetition rate of $20 \mathrm{~Hz}$ for a duration of $1 \mathrm{~min}$. The laser source reaches the target from the top surface of a cuvette as illustrated in Fig. 1C.

\section{Results}

The plasma produced in the interaction between the highintensity laser beam and oxygen is visible in optical images in Fig. 2A and in its spectral shape in Fig. 2B. The picture shows a plasma having a spheroidal shape and a photon emission in the visible-NIR region with 5 lines at 1.5, 1.97, 2.12, 2.23, and $2.44 \mathrm{eV}$. The absence of UV bands indicates the negligible presence of high energetic radiation. Furthermore, a Faraday cup reads a negative current of about $40 \mathrm{pA}$ in all the regions around the plasma at a distance of $10 \mathrm{~cm}$ from the plasma center, indicating the presence of electrons produced in the plasma and isotropically accelerated.

Luminescence emitted from the pure Gold target (see Fig. 2C for the EDX analysis and Fig. 2D for a luminescence spectrum) indicates the presence of two bands at 2.06 and $2.32 \mathrm{eV}$ (530 and $599 \mathrm{~nm}$ ), both attributed to Gold plasmon resonance induced by irradiation of electrons with a mean energy in the range of $5 \mathrm{keV}-30 \mathrm{keV}$ $[14,15]$. At a laser repetition rate of $100 \mathrm{~Hz}$, the emission of $2.5 \times 10^{2}$ photons/shot at $530 \mathrm{~nm}$ (each spectrum was collected during $120 \mathrm{~s}$ and normalized to $1 \mathrm{~s}$ ) produces an electron incidence of $2.5 \times 10^{8}$ 
A)

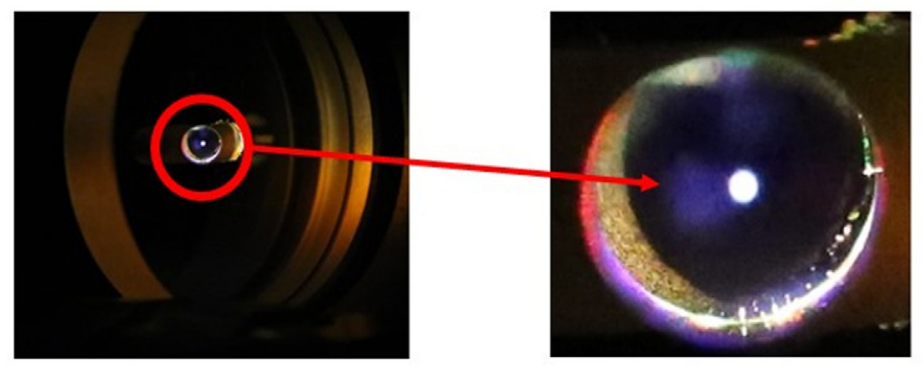

B)

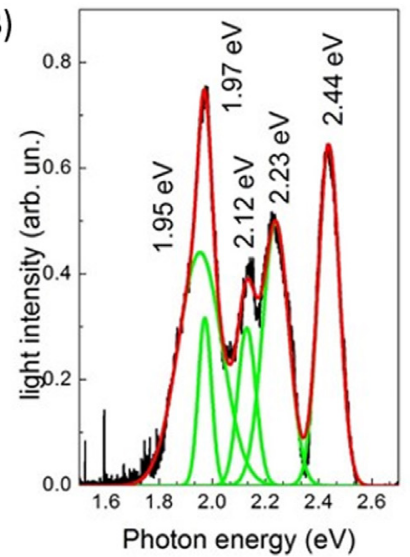

C)

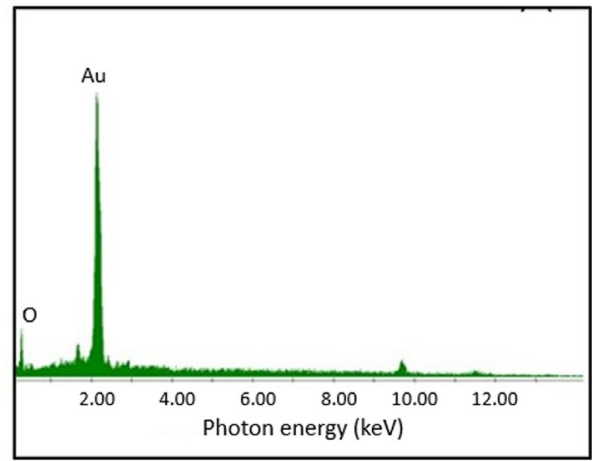

D)

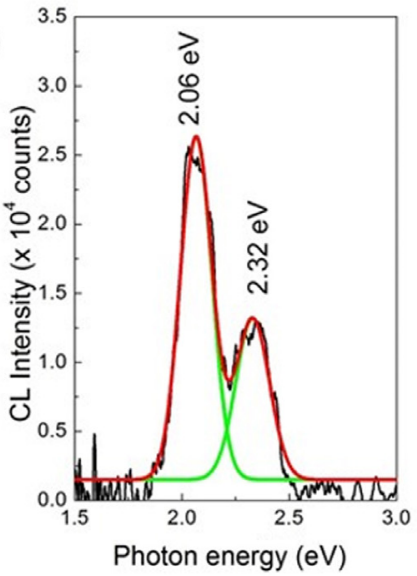

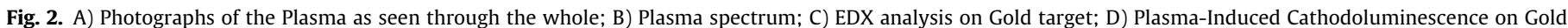
target.
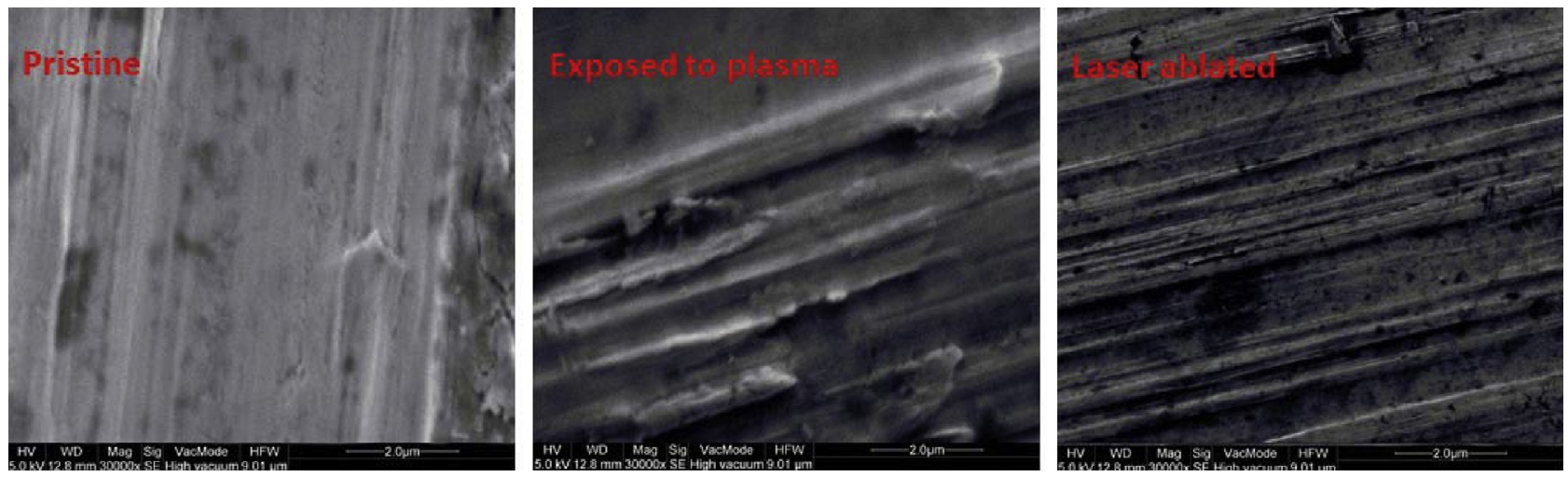

Fig. 3. SEM images of pristine, plasma exposed, and laser ablated Tantalum.

electrons/s (about $40 \mathrm{pA}$ - the probability of plasmon emission from Gold was estimated in $10^{-4}$ photons per incident electron [17]).

Morphological analysis performed on the Tantalum targets exposed individually to both methods, the laser-ablation and the plasma stress method (see Fig. 3 for the SEM images and Fig. 4 for the AFM images) shows that the flat surface of the non-exposed Tantalum becomes irregular after irradiation (see Fig. 3 and Fig. 4). The surface roughness changes from $3 \mathrm{~nm}$ of the pristine Tantalum to about $60 \mathrm{~nm}$ for the exposed targets with an irregular erosion that varies from a minimum of $200 \mathrm{~nm}$ to a maximum of $30 \mu \mathrm{m}$ (see 3D AFM images in Fig. 4 and the result summary in Table 1).

All our results indicate that the stress induced on the material surface by the plasma radiation in the first $10 \mathrm{~h}$ of exposure is very similar to what induced within one minute of laser ablation. The precise description of the ablation mechanism is not
Table 1

Summary of the morphological analysis.

\begin{tabular}{llll}
\hline & Pristine & Plasma exposed & Laser ablated \\
\hline Roughness & $3.15 \mathrm{~nm}$ & $59.8 \mathrm{~nm}$ & $57.5 \mathrm{~nm}$ \\
Erosion & & From $30 \mu \mathrm{m}$ to $200 \mathrm{~nm}$ & From $30 \mu \mathrm{m}$ to $200 \mathrm{~nm}$ \\
\hline
\end{tabular}

simple and multiple fragmentation processes are likely to be at the base of the process. Considering the laser ablation stress testing, only three kind of thermal processes can explain the material detachment from an irradiated target: vaporization, normal boiling and "explosive boiling", depending on the laser parameters (i.e. energy, fluence, and pulse duration) [16-18]. All these mechanisms are based on the fast change of the target temperature, which causes both, a rapid evaporation and detachment of hot atoms, vapours and liquid drops from the surface in a non-thermodynamic 

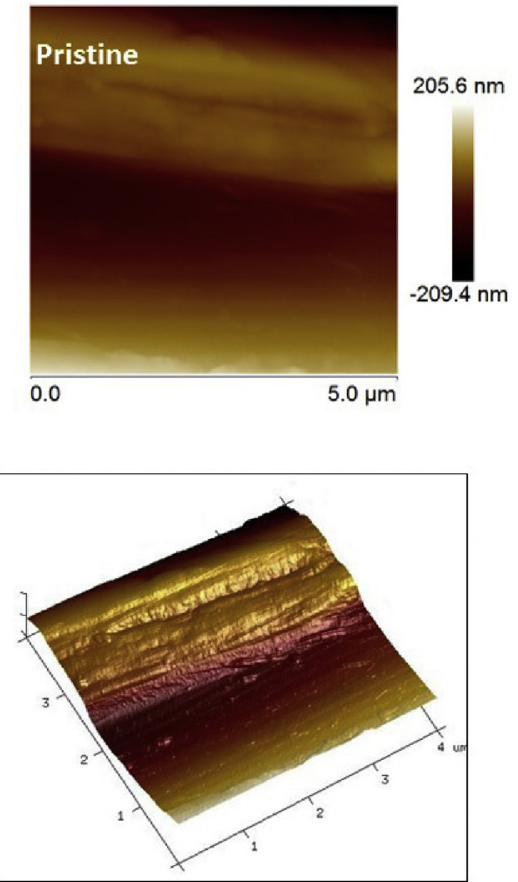
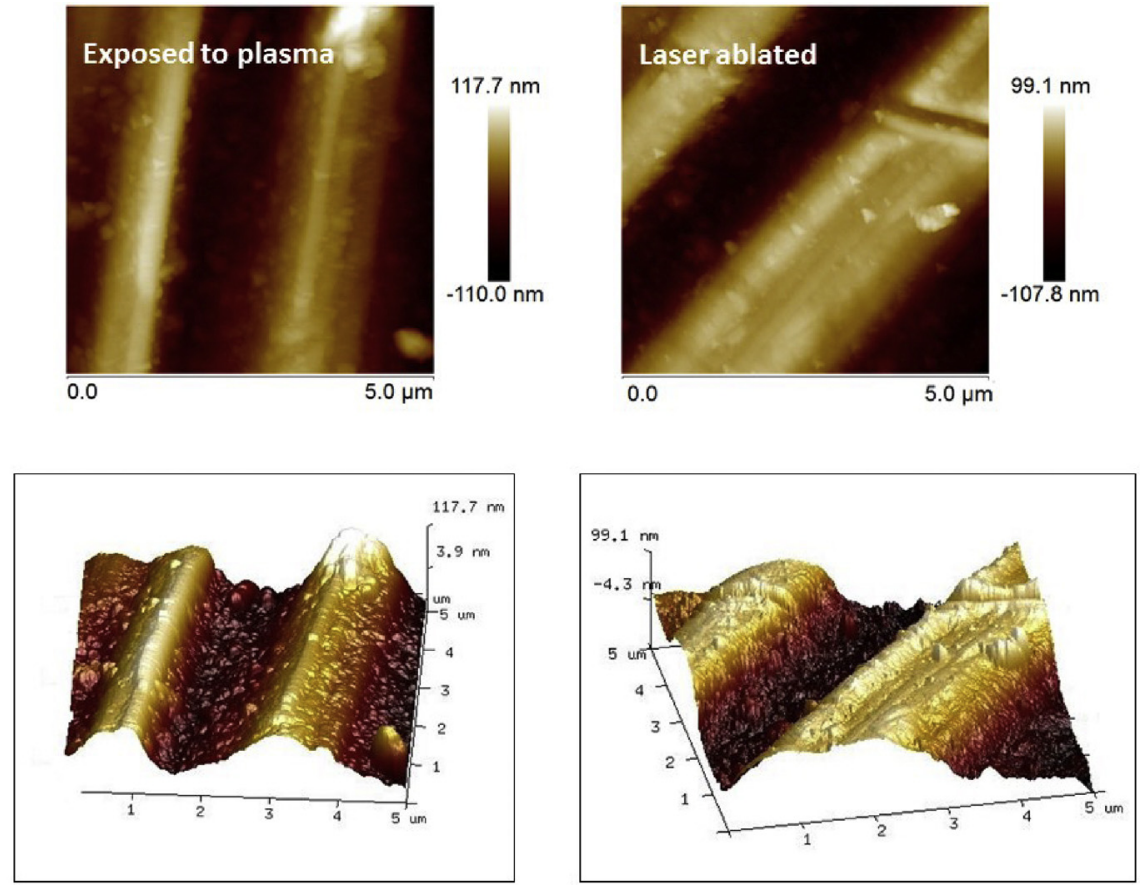

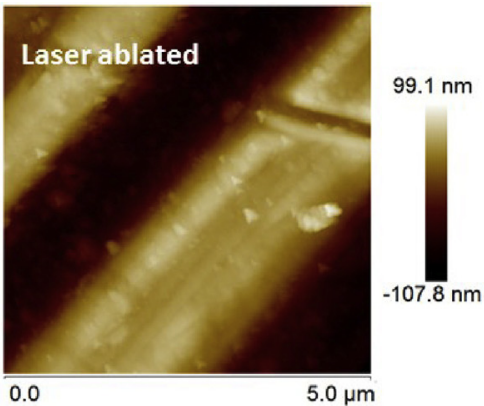

0.0

Fig. 4. AFM images of pristine, plasma exposed, and laser ablated Tantalum.

equilibrium condition. For the case of the plasma irradiation, the thermodynamic conditions are very different. The plasma radiation reaches the target surface with a pulse duration in the order of fs-ns (we hypothesize a pulse duration in the order of the laser pulse duration). The irradiation with electrons having an energy in the order of tens of $\mathrm{keV}$ does not cause considerable changes in temperature for the sample : a simple thermodynamic analysis for Tantalum indicates a temperature variation in the order of $\mathrm{mK} / \mathrm{s}(3 \mathrm{~K} / \mathrm{h})$. In these conditions, the thermodynamic equilibrium is stable and the vaporization and boiling phenomena do not occur, similar to the case of laser ablation with fs-lasers. In these conditions, the ablation mechanism is generically defined as a "fragmentation" and consists of the detachment of hot atoms, vapours and liquid drops under equilibrium conditions. The beta radiation reaches the surface causing a shockwave, which stimulates the detachment of matter from the target surface. Our experimental results show an ablation rate of about $1 \mathrm{~nm} / \mathrm{s}$, indicating a slow surface erosion process. However, this erosion process damages any plasma facing material, and causes an erosion higher than what obtained on typical Magnetic Confinement Fusion (MCF) facilities [19].

\section{Conclusions}

In this work, we investigated the damage produced in materials exposed to laser generated plasma in high power laser experiments. We demonstrated that the plasma exposure generate an erosion of surface, with an ablation rate of about $1 \mathrm{~nm} / \mathrm{s}$. We compare $10 \mathrm{~h}$ of plasma exposure with $1 \mathrm{~min}$ of ns-laser ablation, obtaining in both cases a surface erosion of $30 \mu \mathrm{m}$, and a change in the surface roughness, which varies from $3 \mathrm{~nm}$ of a flat target to about $60 \mathrm{~nm}$ for the stressed materials. The surface stress can be explained in terms of fragmentation of the surface in conditions of thermodynamic equilibrium. The estimated surface damage rate can give crucial information for the definition of safety parameters in high-intense laser experiments, suggesting for the plasma facing materials of these experiments the same safety conditions adopted for Magnetic and Inertial Confinement Fusion facilities.

\section{References}

[1] J. Fuchs, P. Antici, E. d'Humières, E. Lefebvre, M. Borghesi, E. Brambrink, C.A. Cecchetti, M. Kaluza, V. Malka, M. Manclossi, S. Meyroneinc, P. Mora, J. Schreiber, T. Toncian, H. Pépin, P. Audebert, Laser-driven proton scaling laws and new paths towards energy increase, Nat. Phys. 2 (2006) 48.

[2] L. Robson, P.T. Simpson, R.J. Clarke, K.W.D. Ledingham, F. Lindau, O. Lundh, T. McCanny, P. Mora, D. Neely, C.-G. Wahlström, M. Zepf, P. McKenna, Scaling of proton acceleration driven by petawatt-laser-plasma interactions, Nat. Phys. 3 (2007) 58.

[3] H. Daido, M. Nishiuchi, A.S. Pirozhkov, Review of laser-driven ion sources and their applications, Rep. Prog. Phys. 75 (2012) 056401.

[4] M. Borghesi, A.J. Mackinnon, D.H. Campbell, D.G. Hicks, S. Kar, P.K. Patel, D. Price, L. Romagnani, A. Schiavi, O. Willi, Multi-MeV proton source investigations in ultraintense laser-foil interactions, Phys. Rev. Lett. 92 (2004) 055003.

[5] T.E. Cowan, J. Fuchs, H. Ruhl, A. Kemp, P. Audebert, M. Roth, R. Stephens, I. Barton, A. Blazevic, E. Brambrink, J. Cobble, J. Fernández, J.-C. Gauthier, M. Geissel, M. Hegelich, J. Kaae, S. Karsch, G.P. Le Sage, S. Letzring, M. Manclossi, S. Meyroneinc, A. Newkirk, H. Pépin, N. Renard-LeGalloudec, Ultralow emittance, multi-MeV proton beams from a laser virtual-cathode plasma accelerator, Phys. Rev. Lett. 92 (2004) 204801.

[6] (a) B. Albertazzi, A. Ciardi, M. Nakatsutsumi, T. Vinci, J. Béard, R. Bonito, J. Bilette, M. Borgesi, Z. Burkley, S.N. Chen, T.E. Cowan, T. Herrmannsdoerfer, D.P. Higginson, F. Kroll, S.A. Pikuz, K. Naughton, L. Romagnani, C. Riconda, G. Revet, R. Riquier, H.-P. Schlenvoigt, I. Yu. Skobelev, A. Ya. Faenov, A. Soloiev, M. Huarte-Espinosa, A. Frank, O. Portugal, H. Pépin, J. Fuchs, Laboratory formation of a scaled protostellar jet by coaligned poloidal magnetic field, Science 346 (2014) 325-328;

(b) P. Patel, A.J. Mckinnon, M.H. Kev, T.E. Cowan, M.E. Foord, M. Allen, D.F. Price, H. Ruhl, P.T. Springer, R. Stephens, Isochoric heating of solid-density matter with an ultrafast proton beam, Phys. Rev. Lett. 91 (2003) 125004.

[7] D.P. Higginson, L. Vassura, M.M. Gugiu, P. Antici, M. Borghesi, S. Brauckmann, C. Diouf, A. Green, L. Palumbo, H. Petrascu, S. Sofia, M. Stardubtsev, O. Willi, S. Kar, F. Negoita, J. Fuchs, Temporal narrowing of neutrons produced by high-intensity short-pulse lasers, Phys. Rev. Lett. 115 (2015) 054802.

[8] M. Roth, D. Jung, K. Falk, N. Guler, O. Deppert, M. Devlin, A. Favalli, J. Fernandez, D. Gautier, M. Geissel, R. Haight, C.E. Hamilton, B.M. Hegelich, R.P. Johnson, F. Merrill, G. Schaumann, K. Schoenberg, M. Schollmeier, T. Shimada, T. Taddeucci, J.L. Tybo, F. Wagner, S.A. Wender, C.H. Wilde, G.A. Wurden, Bright laser-driven neutron source based on the relativistic transparency of solids, Phys. Rev. Lett. 110 (2012) 044802.

[9] K.W. Ledingham, P.R. Bolton, N. Shikazono, C.M.C. Ma, Towards laser driven hadron cancer radiotherapy: a review of progress, Appl. Sci. 4 (3) (2014) 402-443.

[10] E.T.J. Nibbering, Science 345 (2014) 147.

[11] L. Yi, A. Pukhov, P. Luu-Thanh, B. Shen, Bright X-Ray source from a laser-driven microplasma waveguide, Phys. Rev. Lett. 116 (2016) 115001. 
[12] W. Holgado, C. Hernández-García, B. Alonso, M. Miranda, F. Silva, L. Plaja, H. Crespo, I.J. Sola, Continuous spectra in high-harmonic generation driven by multicycle laser pulses, Phys. Rev. A 93 (2016) 013816.

[13] S. Payeur, S. Fourmaux, B.E. Schmidt, J.P. MacLean, C. Tchervenkov, F. Légaré, M. Piché, J.C. Kieffer, Generation of a beam of fast electrons by tightly focusing a radially polarized ultrashort laser pulse, Appl. Phys. Lett. 101 (2012) 041105.

[14] T. Coenen, E.J.R. Vesseur, Albert Polman, Angle-resolved cathodoluminescence spectroscopy, Appl. Phys. Lett. 99 (2011) 143103.

[15] F.J. García de Abajo, Optical excitations in electron microscopy, Rev. Mod. Phys. 82 (2010) 209
[16] K.S.-T.D. von der Linde, The physical mechanisms of short-pulse laser ablation, Appl. Surf. Sci. 1-10 (2000) 154-155.

[17] P. Lorazo, L.J. Lewis, M. Meunier, Thermodynamic pathways to melting, ablation, and solidification in absorbing solids under pulsed laser irradiation, Phys. Rev. B: Condens. Matter Mater. Phys. 73 (2006) 134108.

[18] L.B. Kiss, J. Soederlund, G.A. Niklasson, C.G. Granqvist, New approach to the origin of lognormal size distributions of nanoparticles, Nanotechnology 10 (1999) 25-28.

[19] A. Hakola, et al., Phys. Scr. T159 (2014), 014027.

Please cite this article in press as: M. Scisciò, et al., Analysis of induced stress on materials exposed to laser-plasma radiation during high-intensity laser experiments, Appl. Surf. Sci. (2017), http://dx.doi.org/10.1016/j.apsusc.2016.12.004 